\title{
Fifth European Antibiotic Awareness Day on 18 November - joining forces to reduce antibiotic
}

\section{resistance}

Eurosurveillance editorial team (eurosurveillance@ecdc.europa.eu) ${ }^{1}$

1. European Centre for Disease Prevention and Control (ECDC), Stockholm, Sweden

Citation style for this article:

Eurosurveillance editorial team. Fifth European Antibiotic Awareness Day on 18 November - joining forces to reduce antibiotic resistance. Euro Surveill. 2012;17(46): $\mathrm{pii}=20314$. Available online: http://www.eurosurveillance.org/ViewArticle. aspx?Articleld=20314

Article published on 15 November 2012

Antibiotics are medicines that are beneficial for mankind and their use in treatment and prevention of bacterial diseases has greatly contributed to reducing the overall burden of such infections. However, already since antibiotics have been used in clinical practice, emergence and spread of antibiotic resistance has represented an obstacle for the effective treatment of infected patients. A growing number of resistance mechanisms and antibiotic-resistant strains have been described and related infections have been increasing in numbers. These trends have been identified as a threat and have thus been watched closely by scientists and public health experts globally to have a clear picture of the magnitude of the problem and its impact on public health, and to identify and implement appropriate control measures.

Extensive coverage in the scientific and general literature illustrates the importance of antibiotic resistance in research and public health practice. On 14 November 2012, entering the simple term 'antibiotic resistance' in PubMed and Google Scholar resulted in the retrieval of 133,163 and over 1,300,000 related publications, respectively. Antibiotic resistance limits the number of options for effective treatment of infected patients. In extreme cases such as infections with carbapenemaseproducing Enterobacteriaceae, alternatives for treatment are limited to only few antibiotics that often are old, have side-effects and limitations for their use.

Antibiotic-resistant bacteria are often responsible for healthcare-associated infections. This is obviously related to antibiotic prescribing practices in hospitals and other healthcare settings, and to poor compliance with infection control measures to prevent spread and patient-to-patient transmission of these bacteria. In this week's issue, Eurosurveillance publishes an article by Zarb et al. in which the authors present the results from a pilot study using a new point prevalence protocol for healthcare-associated infections and antimicrobial use in European acute care hospitals. The results from participating hospitals in 23 countries show that $7.1 \%$ of patients had a healthcare-associated infection, and $34.6 \%$ received at least one antimicrobial agent [1].
Healthcare-associated infections and antibiotic resistance are closely related issues that concern patients, physicians, healthcare providers and public health experts. Due to their associated morbidity and mortality, they lead to a high strain on individuals and health systems. For example it is estimated that in the European Union (EU) alone, the excess hospital stay attributable to selected common multidrug-resistant infections in hospitals amounts to 2.5 million days and 25,000 patients die each year as a result of these infections [2].

Acknowledging the importance of the subject, the EU Commission formulated a strategy against Antimicrobial Resistance and EU Health Ministers adopted Council recommendations on the prudent use of antimicrobial agents in human medicine already in 2001 [3,4] and many more initiatives followed. Last year, the European Commission released its Action plan against the rising threats from antimicrobial resistance [5]. Another initiative is the European Antibiotic Awareness Day (EAAD) that provides a platform and support for national campaigns on the prudent use of antibiotics [6]. This European health initiative, coordinated by the European Centre for Disease Prevention and Control (ECDC) in Stockholm, has grown over the years and new important partners have joined. The first EAAD took place on 18 November 2008 and has been marked at the same date also in the following years. While the first year saw 32 countries participating, in 2012, over 40 countries have started or will launch activities around 18 November when the fifth EAAD takes place. Moreover, in 2012, the World Health Organization Regional Office for Europe supports the campaign actively for the first time and a range of activities have also been organised this week in the United States, in Canada and in Australia [7-9].

In the run up of the day, and in previous years much activity has been ongoing in mass and social media that should have resulted in increasing awareness of the problem of antibiotic resistance and the need to use 
antibiotics prudently, i.e. only when indicated, among the general public and among health professionals.

An initial evaluation of EAAD took place in 2009, showing strong political and stakeholder support [10], however, in a next step it will be important to measure the success of the initiative and see whether awareness has been transformed into action. Such action could be indicated for example by more adequate prescribing by doctors and less self-medication by patients, and as a result less antibiotic consumption. Obtaining the respective data and attributing them to efforts associated with the EAAD as one important element in the fight against antibiotic resistance is a challenge. Visible results can only be expected over time and evaluation may require specific studies and analyses. Eurosurveillance will keep on following the evolution of the EAAD and publish articles that contribute to give insight into the situation and related issues connected with antimicrobial resistance and healthcare-associated infections.

\section{References}

1. Zarb P, Coignard B, Griskeviciene J, Muller A, Vankerckhoven V, Weist K, et al. The European Centre for Disease Prevention and Control (ECDC) pilot point prevalence survey of healthcare-associated infections and antimicrobial use. Euro Surveill. 2012;17(46): pii=20316. Available from: http://www. eurosurveillance.org/ViewArticle.aspx?Articleld =20316

2. European Centre for Disease Prevention and Control (ECDC) / European Medicines Agency (EMEA). Joint Technical Report. The bacterial challenge: time to react. Stockholm: ECDC; Sep 2009. Available from: http://www.ecdc.europa.eu/ en/publications/Publications/0909_TER_The_Bacterial_ Challenge_Time_to_React.pdf

3. European Commission. Communication from the Commission of 20 June 2001 on a Community strategy against antimicrobial resistance. [Accessed 15 Nov 2012]. Available from: http://eurlex.europa.eu/LexUriServ/LexUriServ.do?uri=CELEX:52001DCo 333:EN:HTML

4. Council of the European Union. Council Recommendation of 15 November 2001 on the prudent use of antimicrobial agents in human medicine (2002/77/EC). Official Journal of the European Communities, 2002 Feb. Available from: http://eur-lex.europa. eu/LexUriServ/LexUriServ.do?uri=0J:L:2002:034:0013:0016:E $\mathrm{N}: \mathrm{PDF}$

5. European Commission. Communication from the Commission to the European Parliament and the Council. Action plan against the rising threats from Antimicrobial Resistance. COM (2011) 748. Available from: http://ec.europa.eu/dgs/ health_consumer/docs/communication_amr_2011_748_en.pdf

6. European Centre for Disease Prevention and Control (ECDC) European Antibiotic Awareness Day (EAAD). Stockholm: ECDC. [Accessed 15 Nov 2012]. Available from: http://ecdc.europa.eu/ en/eaad/Pages/Home.aspx

7. Centers for Disease Control and Prevention (CDC). Get Smart About Antibiotics Week. Atlanta: CDC. [Accessed 15 Nov 2012]. Available from: http://www.cdc.gov/getsmart/index.html

8. AntibioticAwareness.ca [Internet]. Antibiotic Awareness Week. [Accessed 15 Nov 2012]. Available from: http:// antibioticawareness.ca/

9. NPS Medicinewise [Internet]. Antibiotic Awareness Week. [Accessed 15 Nov 2012]. Available from: http:// www.nps.org.au/bemedicinewise/antibiotic_resistance/ antibiotic awareness week

10. Earnshaw S, Monnet DL, Duncan B, O'Toole J, Ekdahl K, Goossens H, et al. European Antibiotic Awareness Day, 2008 - the first Europe-wide public information campaign on prudent antibiotic use: methods and survey of activities in participating countries. Euro Surveill. 2009;14(30):pii=19280. Available from: http://www.eurosurveillance.org/ViewArticle. aspx?Articleld $=19280$ 